\title{
Tool material, tool wear and machined hole quality evaluation at CFRP drilling
}

\author{
Claudiu-Ioan Jugrestan ${ }^{1, *}$, Marcel-Sabin Popa $^{1}$, Stefan Sattel ${ }^{2}$, Adina-Elena Cotarga ${ }^{1}$, \\ Ovidiu-Virgil Veres ${ }^{1}$ and Camil-Octav Chetreanu Don ${ }^{3}$ \\ ${ }^{1}$ Technical University of Cluj-Napoca, Faculty of Mechanical Engineering, Department of \\ Manufacturing Engineering, BulevardulMuncii 103-105, Cluj-Napoca, Romania \\ ${ }^{2}$ Gühring KG, Herderstraße 50-54, Albstadt, Germany \\ ${ }^{3}$ Gühring S.R.L., Transilvaniei 12, Baciu, Romania
}

\begin{abstract}
Because of increasingly stricter safety rules, requirements regarding the quality of the components used in the airline industry have increased. Besides the materials used in aircraft components and areas where they are machined, these components must comply certain standards for quality and tolerances of the machined surfaces.Due to high hardness of carbon fibers, hole machining in carbon fiber reinforced plastics has always been a challenge. Wear that occurs in the cutting tool leads to the appearance of workpiece defects such as delamination, peeling, fiber pulling out, etc. Besides cutting tool geometry, a very important role on tool wear, it is owned by the material from which it is made. This paper will make a quantitative assessment of defects that occur in the process of CFRP (carbon fiber reinforced plastics) drilling and a cutting tool wear evaluation. In order to obtain conclusive results for this study will be used three drill bits with the same geometry but different carbides.The aim of this paper is to find which one of this three carbide used is more feasible for holes machining in composite materials reinforced with carbon fibers.
\end{abstract}

\section{Introduction}

In the entire world, the growing demand for new materials with new or better chemical and physical properties has increased a lot in the last 20 years. Due to their weight-specific properties, low thermal expansion, high chemical resistance, etc. the CFRP are used in a wide range.

The main fields where these materials are usedare those that are based on weight reduction. Some of those are aerospace and automotive industry, but also the wind energy industry. In the Figure 1, in a report made by Kraus and Kuehnel, are shown the quantities, in tones, used in different areas in 2014 [1]. In the same report is made a forecast regarding the produced quantities of CFRP, annually, by 2021. Can be observed that there are a lot of fields, where, the composite materials are replacing conventional materials. A good example is the manufacturing of a plane fuselage, where until last years were used aluminium alloys that now are replaced by composite materials, especially composite materials reinforced with carbon fibers or fiberglass.

${ }^{*}$ Corresponding author: jugrestan_claudiu@yahoo.com 

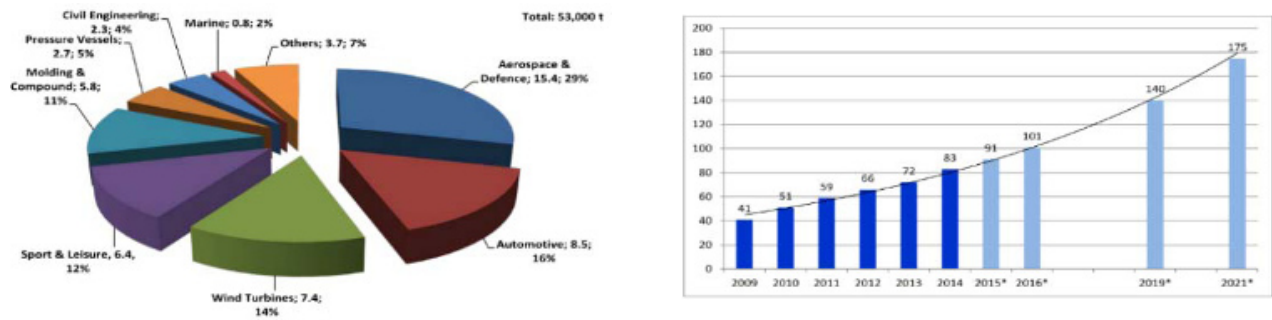

Fig.1. CFRP application fields and CFRP demand forecast [1].

Accordingly with Islam [2], drilling is one of the most used operation in carbon fiber reinforced plastics machining. In his doctoral thesis, he showed that are acoustic panels that can incorporate up to 100.000 holes with diameters between 3-6 mm.

Because of the use on a raising scale of these types of materials, also the cutting tools industry is forced to come up with new solutions for their machining. Compared to conventional materials, at CFRP machining must be taken into account other defects that can occur, as delamination, pull outs, fibers projection, pyrolysis, etc., partially represented in Figure 2 [3].

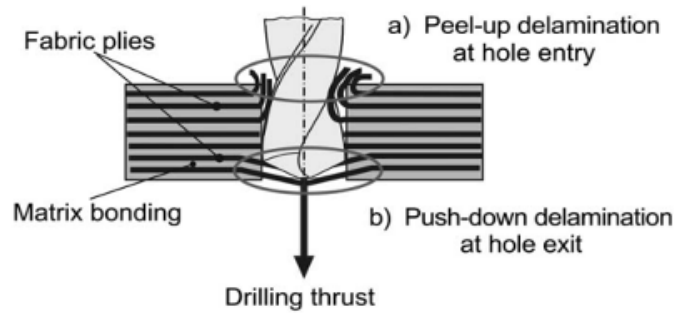

Fig. 2. Hole quality defects [3].

These problems occur, primarily, due to inhomogeneity that composite materials reinforced with carbon fibers, due tothe cutting tools geometry, their wear and due tocutting parameters that are used.

\section{Experimental work}

\subsection{Equipment}

For the experiments was used a Matsuura VX-1000 CNC machining center with the characteristics shown in Table 1.

Table 1. CNC characteristics

\begin{tabular}{|l|l|l|l|l|l|r|}
\hline Spindle motor power & $\mathrm{kW}$ & $15-22$ & & X-Axis Travel & $\mathrm{mm}$ & 1020 \\
\cline { 1 - 2 } Spindle speedrange & $\mathrm{min}^{-1}$ & $50-15000$ & & Y-Axis Travel & $\mathrm{mm}$ & 610 \\
\hline Feedrate & $\mathrm{mm} / \mathrm{min}$ & $1-20000$ & & X-Axis Travel & $\mathrm{mm}$ & 610 \\
\hline
\end{tabular}

For delamination measurement was used a Keyence VHX-5000 digital microscope, equipped with a $4800 \times 3600$ pixels super high resolution camera. Tool wear was measured 
with an Aliconanon-contact, optical, three-dimensional scanning, based on focus-variation equipment.

\subsection{Workpiece material}

For test, the M21/34\%/UD194/IMA-12K material, produced by Firma Hexcel was selected. In present, this material is used for the Airbus A380 civilian airplane fuselage construction. The main physical and mechanical properties are shown in Table 2.

Table 2. Material properties [4]

\begin{tabular}{|l|c|c|}
\hline Properties & Units & M21/34\%/UD194/IMA-12K \\
\hline Fiber Weave/DU Fiber Mass & $\mathrm{g} / \mathrm{m}^{2}$ & 194 \\
\hline TheoreticalCalculatedCuredPlyThickness & $\mathrm{mm}$ & 0,184 \\
\hline TheoreticalCalculated Fiber Volume & $\%$ & 59.2 \\
\hline ResinDensity & $\mathrm{g} / \mathrm{cm}^{3}$ & 1.28 \\
\hline Fiber Desnsity & $\mathrm{g} / \mathrm{cm}^{3}$ & 1.78 \\
\hline TheoreticalCalculated Laminate Density & $\mathrm{g} / \mathrm{cm}^{3}$ & 1.58 \\
\hline Tension Strength & $\mathrm{MPa}$ & 3050 \\
\hline Tension Modulus & $\mathrm{GPa}$ & 178 \\
\hline CompressionStrength & $\mathrm{MPa}$ & 1500 \\
\hline CompressionModulus & $\mathrm{GPa}$ & 146 \\
\hline
\end{tabular}

\subsection{Cutting tools}

In order to have conclusive results, for this study will be used three drills with the same geometry but made from three different carbides. Alsothe cutting parameters will be the same for all tests: $v c=100 \mathrm{~m} / \mathrm{min} ; \mathrm{f}=0.06 \mathrm{~mm} / \mathrm{U} ; \mathrm{vf}=300 \mathrm{~mm} / \mathrm{min} ; \mathrm{n}=5013 \mathrm{rev} / \mathrm{min}$.

\subsubsection{Drill geometry}

In his dissertation thesis, Barbagallo has shown that the step drills have better result in CFRP drilling. He has explained that the drill chisel edge and the axial force, which acts on the last material layers, have an important role on delamination produced by the first drill diameter [5].
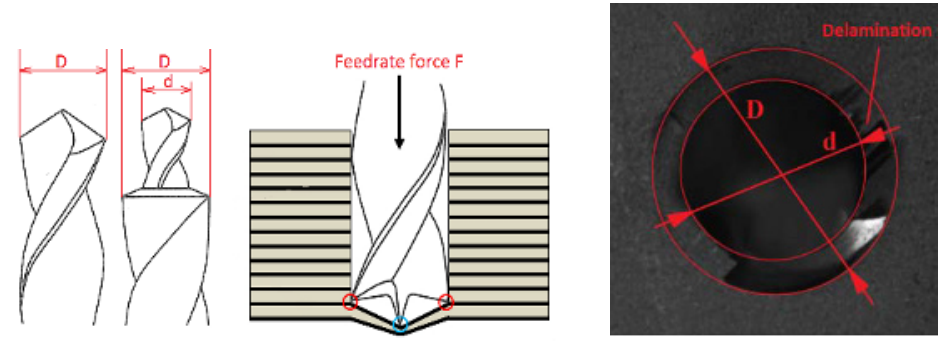

Fig. 3. Drill geometry (left) [5] and machining dynamics (center and right).

The tested drills will have two steps, with $\mathrm{d}=4.75$ and $\mathrm{D}=6.35$. The results will be compared with previously tests made with an RT100U, article 7924 drill, provided by the Gühring Company, used for metallic materials machining. 


\subsubsection{Cutting tools materials}

The tested drills are produced from three different WC-Co carbide grades, Type 1 $(0.7 \mu$ mgrainsize), Type $2(0.6 \mu \mathrm{m})$, and Type $3(0.5 \mu \mathrm{m})$, , produced by Firma Gühring[6]. In table 3 are described the characteristics of these three carbide grades.

Table 3. Carbide grades [6]

\begin{tabular}{|c|c|c|c|c|c|}
\hline \multirow[t]{2}{*}{ Carbide grade } & \multicolumn{2}{|c|}{$\begin{array}{c}\text { Chemical } \\
\text { composition (\%) }\end{array}$} & \multirow{2}{*}{$\begin{array}{c}\text { WC grainsize } \\
(\mu \mathrm{m})\end{array}$} & \multirow{2}{*}{$\begin{array}{l}\text { Density } \\
\left(\mathrm{g} / \mathrm{cm}^{3}\right)\end{array}$} & \multirow{2}{*}{$\begin{array}{l}\text { Hardness } \\
\text { (HV 30) }\end{array}$} \\
\hline & WC & $\mathrm{Co}$ & & & \\
\hline Type 1 & 92 & 8 & 0.7 & 14.55 & 1710 \\
\hline Type 2 & 92 & 8 & 0.6 & 14.55 & 1790 \\
\hline Type 3 & 95 & 5 & 0.5 & 15 & 2010 \\
\hline
\end{tabular}

\section{Tests and results}

In this paper was aimed to obtain holes where the delaminated area $\left(\mathrm{A}_{2}\right)$, calculated with relation 2 , must be maximum $2 \%$ from the machined hole area $\left(A_{1}\right)$, calculated with relation 3. For that, relation 1 will be taken into account:

$$
\begin{aligned}
& 2 \% \geq\left(A_{2} / A_{1}\right) * 100 \\
& A_{2}=a_{1}+a_{2}+\ldots a_{n} \\
& A_{1}=\pi * r^{2}=31.6 \mathrm{~mm}^{2}
\end{aligned}
$$

where $r$ is the machined hole radius $(3.175 \mathrm{~mm})$ and $a_{1}, a_{2}, \ldots a_{n}$ are the errors surfaces.

Also the number of machined holes with the RT100U drill will be taken as a percentage of $100 \%$ and depending on it the others three drills will be evaluated. In the Figure 4 are pictures made with the first machined hole and with the hole where the test was stopped, for each drill.

In Figure 4 are represented the errors that has occurred during a test made by Gauggel in his dissertation thesis[7]. The tests were made in the same workpiece material and with the same Gühring RT100U drill[8]. These results will be taken as reference for future tests.

In Figure 5 are shown, in the left side, the machined holes, together with the surfaces where the errors has occurred. Also, in the same figure, in the right side, by 3D scanning, was made a comparison between the initial drill cutting edge and the cutting edge after the tests were stopped.

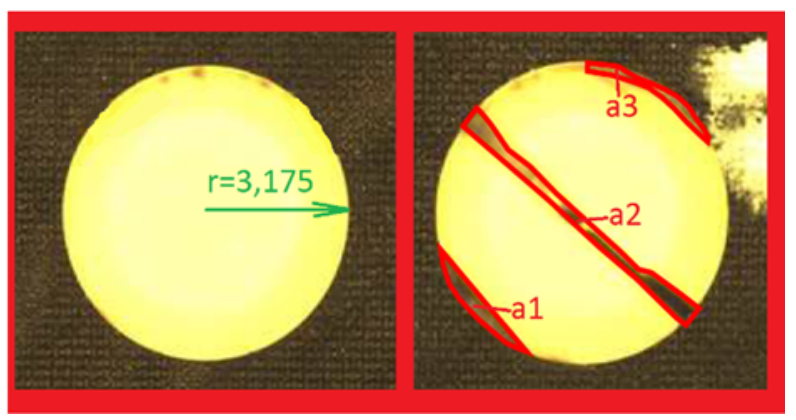

Fig. 4. First hole / last hole machined with RT100U [7]. 


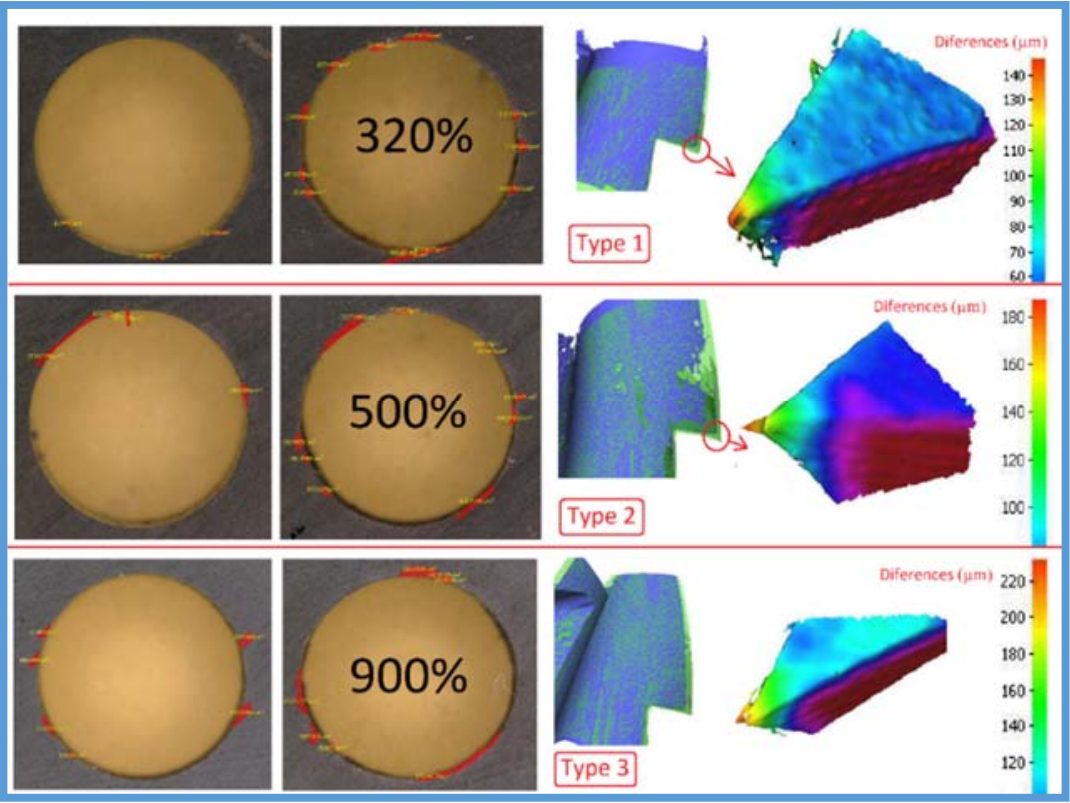

Fig. 5. Machined holes errors (left) and tool wear (right).

The 3D scan was made with the Alicona equipment. Before starting the tests, the drills were 3D scanned, obtaining the green contour. The obtained image was overlapped on the scan made at the end of the tests (blue contour) thus obtaining the wear values "W", represented in Figure 6.

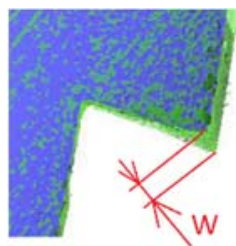

Fig. 6. Alicona 3D

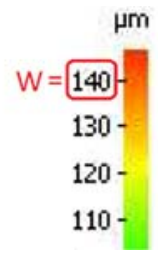
.

After the chart from Figure 7 analyzation, can be seen that with step drills can be obtain results with up to $450 \%$ better than using conventional drills used for the metallic materials machining. Also can be observed that the carbide grade has an important role on the

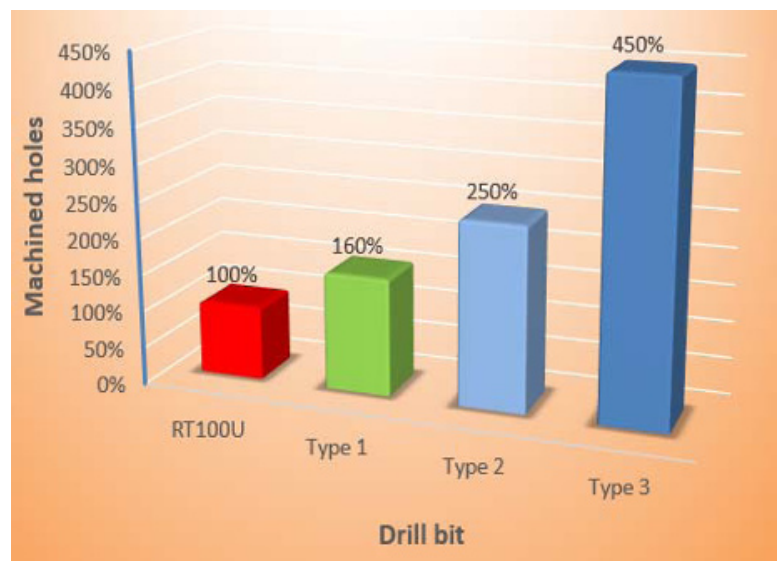

Fig. 7. Comparison between conventional and step drills. number of machined holes. Although all three carbide grades have the same components, the percentage of those components has a significant influence on final results. The Type 3 drill has the WC content bigger than the other two carbides, and that makes the cutting edge tougher. Because of this, the carbon fibers abrasiveness do not wear so fast the drill cutting edges. In the same Figure 6 is visible that hole number made with the Type 3 drill is almost double, compared 
with the Type 2 . The Type 1 and Type 2 are two carbides with the same properties and the same percentage of components, the only difference between them being only the WC grain size. Accordingly with Faraz, as main cutting edge radius is smaller, the errors surface will be reduced [3]. Also it makes sense that as the smaller the WC grains are, a better cutting edge sharpening can be obtain. From the chart above, between the results obtained with these two drills is a big difference. The Type 2 grain size is with $0,1 \mu \mathrm{m}$ smaller that the Type 1, but this small difference had substantially influenced the final results as is visible in the chart from Figure 6.

\section{Conclusions}

In the last 20 years, the carbon fiber reinforced plastics had started to replace the conventional materials in many industrial applications. Because of that in this paper was made, firstly, an assessment of the problems that appear during the holes machining regarding the workpiece quality and then regarding the cutting tool wear. In order to reduce the problems regarding the workpiece and the tool, special drill geometries were tested and compared with classical geometries. Was observed that the classical drills are not feasible for the CFRP machining because they produce large delaminated areas compared with the step drills. For the step drills was noticed that the delaminated area produced by the first diameter (d) is cut off by the tool nominal diameter (D).Also this paper reveals that the tool material is critical for the tool life. The Type 3 drill, that have a bigger concentration of $\mathrm{WC}$, have performed better than the others, the conclusion being that the tool life is strictly related to the tool material hardness. A correlation was also found between the WC grain size and the machined hole quality. The Type 1 and Type 2 drills have the same chemical composition, density and hardness, the only difference between them being only the WC grain size. After the tests, is visible the fact that the Type 2 drill, with $0.6 \mu \mathrm{m}$ grain size, gave with more than $150 \%$ better results than the Type 1 drill, with $0.7 \mu \mathrm{m}$ grain size. The explanation is that the smaller the carbide grains are, the better the cutting edges can be sharpened, in the drilling process the carbon fibers being cut easier.

\section{References}

1. T. Kraus, M. Kühnel, E. Witten, Composites market report 2015, (Federation of Reinforced Plastic, 2015)

2. S.E.M.S. Islam, Drilling of carbon fibre reinforced plastic composites, (Doctoral Thesis, University of Birmingham, 2010)

3. A. Faraz, D. Biermann, K. Weinert, International Journal of Machine Tools \& Manufacture, 49 (2009)

4. Information brochure, Hexcel, www.hexcel.com, (2017)

5. S.F. Barbagallo, Optimization of the cutting geometries of a solid carbide drilling tool for the processing of CFRP composite materials (in German), (Technology and Management Faculty, Ravensburg-Weingarten, 2014)

6. Gühring Catalog, HARTMETALLE for precision tools. Price list no.42. Hard metal grades for basic tools (in German), (2011)

7. C.W. Gaugel, Development of high-performance cutting tool for the processing of CFRP composite materials (in German), (Albstadt-Sigmaringen University, 2013)

8. Gühring Catalog, Gühring drilling, (2015). 